\title{
Design of Virtual Reality Combined with Blended Experimental Teaching Mode
}

\author{
Jianming Liu * \\ Computer Department \\ Weifang Medical University \\ Weifang, 261053, China \\ Shujuan Liang ${ }^{\triangle}$ \\ Clinical Medical Department \\ Weifang Medical University \\ Weifang, 261053, China
}

\author{
Qing Wang ${ }^{\triangle}$ \\ Clinical Medical Department \\ Weifang Medical University \\ Weifang, 261053, China \\ Zhennan Zhang \\ Computer Department \\ Weifang Medical University \\ Weifang, 261053, China
}

\begin{abstract}
The development of education informatization has brought about major changes in the forms of education and learning methods. Blended learning will be the key technology to promote higher education in the next one or two years. In order to improve the effect and validity of experimental teaching, this study constructed a teaching mode of virtual reality combined with blended experimental. It realized the blended experimental teaching of 'online and offline learning, simulation training and real experiment'. Research data suggested that the students trained their experimental thinking and skills through selfdirected learning and communication inquiry. The teacher guided the student's learning process and comprehensively evaluated the student's experimental results. Thus, this teaching model has made the student-centered teaching possible and has achieved good experimental results.
\end{abstract}

Keywords-Virtual Reality Combined; Cloud Platform; Blended Teaching; Experimental Teaching Mode

\section{INTRODUCTION}

The development of education informatization has brought about major changes in the forms of education and learning methods. It had a tremendous impact on traditional educational ideas, concepts, models, contents and methods. Blended learning will be the key technology to promote higher education in the next one to two years[1]. In the past few years, people's concept of online learning had changed, and more students and teachers were interested in it. It was regarded as a viable alternative to face-to-face learning. Blended learning combined the best practical experience of online learning and face-to-face learning[2]. With the increasing number of digital learning platforms, more and more colleges adopt Blended learning. Many research results showed that this model can improve creative thinking, enhance independent learning ability, cultivate students' ability to adjust their learning, and tailor their learning program according to their own needs. This paper constructed a blended experimental teaching model which combines online virtual experiment with offline real experiment. Through this model, students can realize the Blended learning of online learning and simulation experiment training, offline real experiment operation through cloud

Sponsor: The 13th Five-Year Education Planning Project of Shandong Province Fund under grant NO. YC201917.

$\triangle$ Co-First Author. platform, and train experimental thinking and experimental skills through independent learning and communication inquiry.

\section{VIRTUAL EXPERIMENTAL ClOUd PlatForm}

\section{A. Cloud Platform}

"Cloud Platform" is an efficient, convenient and real-time interactive distance learning network platform based on cloud computing technology[3]. Users can quickly and efficiently share voice, video and data files with students, teachers, parents and other users all over the world by using simple and easy-to-use operation through the Internet interface[4]. The introduction of new media technology into cloud platform has changed the single teaching mode, strengthened participation and facilitated the introduction of new media technology[5]. It is conducive to improve the students' interest in learning and carry out group collaboration and inquiry activities.

\section{B. Virtual Experimental Cloud Platform}

The virtual experiment cloud platform is divided into teacher users and student users. Teachers log on to the cloud platform to realize the design and management of experimental courses, the management of students, the examination of students' experimental design and experimental reports, and the online teaching activities with students[6]. After students log in they can check the objectives, requirements, tasks and contents of the experiment, understand the method of using the experimental instrument' using and laboratory notes, and view the online demonstration teaching of the experiment, which can realize the online simulation training of the experiment, submit the experiment design and experiment report, and carry out online communication with teachers and classmates. In short, the virtual experimental cloud platform has the conditions to carry out Blended experimental teaching.

Cloud platform teaching embodies the student-centered teaching concept. All teaching and learning resources are placed on the unified digital cloud platform to share. Students can learn online and interact with others independently through mobile learning terminals and under the guidance of teachers[7]. 
Cloud platform teaching embodies the concept of personalized learning. Cloud platform makes teaching and learning in the same position, creating a ubiquitous learning space for students[8]. Students can enter the learning platform at any time to preview or review the class, exchange and discuss with others, and submit homework or mutual evaluation. They can also use the platform to carry out extended learning and consolidated knowledge re-learning.

The cloud platform can also analyze students' learning in real time. Using the analysis technology, it can track the students' learning behavior and get the evaluation of students' learning hobbies, characteristics, behavior and quality through tracking information[9]. It can provide personalized suggestions for students' further learning and reference for the improvement of teachers' teaching methods.

\section{DESIGN AND IMPLEMENTATION OF BLENDED EXPERIMENT TEACHING ON CLOUD PLATFORM}

About the hybrid experimental teaching mode of cloud platform, the whole teaching process is divided into three stages. Pre-experiment: students' self-learning and virtual training stage through the cloud platform. In the experiment: the specific operation stage in the laboratory. After the experiment: experimental summary and report submission stage. Different from traditional experimental teaching, the first and the third stage of hybrid experimental teaching based on cloud platform are completed through cloud platform, and the second stage is carried out in the laboratory. The Blended experimental teaching mode based on cloud platform is shown

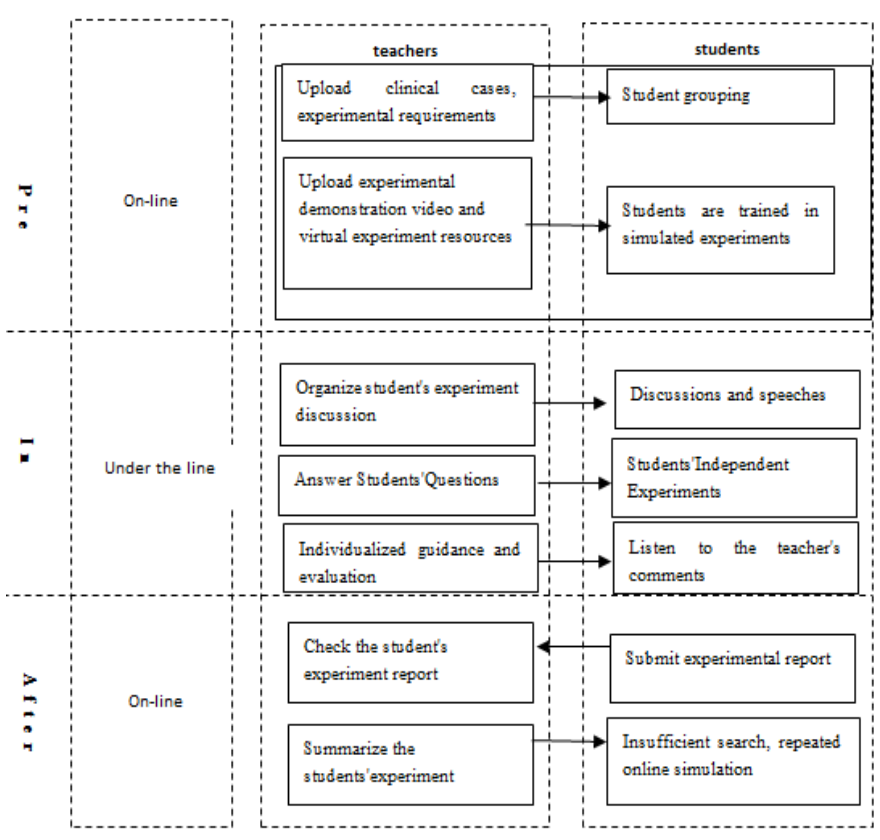

Fig.1. Blended experimental teaching model based on cloud platform

\section{A. Pre-experiment}

Teachers upload experimental instructions such as objectives, requirements, tasks and steps of the experiment, or the corresponding experimental demonstration videos and virtual experiments. Students log on to the cloud platform according to their school number, study independently online and watch experimental demonstration videos. For the unfamiliar experimental instruments, they can online inquire the method of application through video. Finally, virtual experiments are used to simulate the process and steps of the experiment online repeatedly. Students can communicate with their classmates and consult teachers online to solve the problems in learning. Teachers can participate in the interactive communication of students through cloud platform, give guidance according to students' questions, check background learning records of students, master learning time and learning process of students, and understand the training effect of students through the process evaluation results of virtual experiment. It is more conducive to provide individualized guidance for students than face-to-face laboratory teaching.

\section{B. In the Experiments}

This is the laboratory operation stage. After the beginning of the experiment, the teacher no longer explains the basic questions such as the purpose, task or steps of the experiment, but concentrates on the solution according to the learning results and problems of the students in the cloud platform. The students discuss and operate the experiment in groups according to the learning content of the cloud platform. They are the organizers of the whole experiment and operation. It is independently completed, training the students' autonomous experimental operation ability. After the first stage of cloud platform online simulation training, the whole experiment process is smooth and orderly. Teachers only give individualized guidance to students when they encounter problems in experiments, and demonstrate the difficulties of operating in a teaching way, so as to guide students to think about the connection between experimental operation and theoretical knowledge.

\section{After the Experiment}

Students write experimental reports and submit them to the cloud platform. Teachers consult students' experimental reports According to the experiment reports, the learning record of cloud platform and the observation of students' experiment operation process in the laboratory, teachers can make a comprehensive evaluation of the students. The evaluation results are fed back to the students through the cloud platform in time. Students can also conduct online self-evaluation and mutual evaluation through the cloud platform. According to the evaluation results of teachers and other students, students can find out the shortcomings in time. Teachers can further improve the experimental resources of cloud platform according to students' opinions. After the experiment, the students can still repeat the training again according to the problems encountered in the experiment through virtual experiment. If the actual experiment operation is needed, the students can apply for the open laboratory to carry out the real experiment operation through the cloud platform.

\section{AdVANTAGES OF BLENDED EXPERIMENTAL TEACHING ON CLOUD PLATFORM}

The Blended experimental teaching mode based on cloud platform realizes the experimental process of "on-line simulation training and off-line real operation", which has obvious advantages compared with traditional experimental teaching. 


\section{A. Changing the Traditional Teaching Mode of "Teacher- Centered" in Experimental Teaching}

The traditional experiment teaching takes the laboratory as the main teaching activity place. Firstly, the teacher explains the experiment purpose, content, matters needing attention, demonstrates the experimental instruments and the key and difficult experimental steps. The traditional teaching and demonstrating is the "teacher-centered" teaching method. Students carry out experiments according to the teacher's requirements and given experimental steps, lacking active thinking, independent learning and training of innovative critical thinking.

Mixed experimental teaching based on cloud platform embodies the "student-centered" teaching mode. The purpose, content, steps of the experiment, the use of instruments and equipment and matters needing attention can be learned independently online through cloud platform. Problems encountered in the learning process can be communicated online with classmates and teachers. In the real experimental operation, students are grouped and operated independently. Teachers no longer teach, but answer questions, coach, summarize and evaluate them pertinently. In this mixed experimental mode, the "learning by doing" is really realized. It greatly improves participation, enthusiasm and interest of students, and effectively improves the experimental results.

\section{B. Shortening the Operation Time of Real Experiment}

In traditional experimental teaching, students need to learn while doing, and their hands-on operation depends too much on laboratory and experimental equipment. In the process of experiment, they need to spend a lot of time familiarizing themselves with the use of some experimental instruments and matters needing attention. Real experiment takes a long time, and some students can't fully experiment in limited experimental classes. There are many problems in the course of the experiment, and the teachers can't answer them in detail. The Blended experimental teaching mode based on cloud platform adopts the form of "flipping" in the experimental classroom. Before the real experiment, students have learnt and communicated through the platform, and even have repeated online simulation training for the experimental steps and the use of instruments and equipment, so as to achieve the overall grasp of the entire experimental process. It shortens the real experiment time and improves the effect of the experiment.

\section{Reflecting the Guiding Role of Teachers}

The mixed teaching mode based on cloud platform can give full play to the guiding role of teachers. Under this kind of teaching mode, the teacher's role changes from knowledge imparting to learning guidance. In the process of students' learning, teachers can participate in students' discussion through cloud platform, supervise students' learning behavior, evaluate students' experimental reports and experimental plans, and timely feedback these all to students. Teachers can also give students specific guidance on the key and difficult points of experimental content in the experimental teaching, help students to operate skillfully and improve their ability to think about problems.
Teachers can better guide students' learning through interaction with students. Because of the differences among the learners, teachers need to guide the learners in different ways Teachers can timely feedback information to students in the cloud platform, and can communicate with students in realtime. Feedback of students' information in time can improve the discourse interaction between students, teachers and students, and can promote the process of social learning. In the process of interaction with students, the teachers acts as learning companions to guide students' learning. They no longer let students accept passively according to their own methods. Students can't only learn knowledge, but also cultivate their creativity and thinking ability in the process of learning.

\section{Realizing the Opening of "Full-Time" Laboratory in Real Sense}

Traditional laboratories are limited by the number of students, teachers, equipment, time and space, and many other factors. It is difficult to achieve a truly complete opening. The on-line experimental cloud platform can break through the space-time limitation, solve the number limitation of students, and realize the complete online opening. Students can know the instructions of the experimental instruments in advance through the experimental cloud platform, and can simulate training repeatedly for the instruments and experimental steps, only aiming at the difficult problems in some experiments according to students. It has realized the open mode of "giving priority to virtual, supplementing by real" and saved manpower and material resources.

\section{QUESTIONNAIRE ANALYSIS OF EXPERIMENTAL EFFECTS}

The blended experimental teaching mode based on cloud platform has been implemented for two years. Questionnaire stars are used to carry out network survey and statistics are carried out through questionnaire analysis function. The results of several key questions are as follows: "Are the blended experimental teaching mode based on cloud platform satisfied?' $32.1 \%$ of the students were very satisfied with the choice, $53.6 \%$ of the students were satisfied with the choice, $9.3 \%$ of the students were basically satisfied with the choice, and $5 \%$ of the students were not satisfied with the choice. This shows that the satisfaction of blended experimental teaching mode based on cloud platform is relatively high. For "whether the experimental cloud platform really plays the role of preexperiment preview and simulation training to improve the experimental results?' $30.3 \%$ of the students choose to play a great role, $58.6 \%$ of the students choose to play a certain role, $10.1 \%$ of the students choose to be general, $1 \%$ of the students choose to play a small role, no one choose to have no effect, indicating that the experimental cloud platform in preexperiment preview, simulation training to improve the experimental effect is remarkable. For 'Is the blended experimental teaching mode based on cloud platform conducive to the development of innovative design experiments?' Twenty-five. $6 \%$ of the students' choices are very favorable, $56.8 \%$ of the students' choices are favorable, $12.6 \%$ of the students' choices are general, $5 \%$ of the students' choices are unfavorable, and no one chooses very unfavorably. For the 
'cloud platform based blended experimental teaching, mode is conducive to improve the efficiency and effectiveness of real experiments, expand the knowledge of students?' $32.5 \%$ of the students' choices are very favorable, $48.3 \%$ of the students' choices are favorable, $17.2 \%$ of the students' choices are general, $2 \%$ of the students' choices are unfavorable, and no one chooses very unfavorably. For 'Is it willing to popularize this teaching mode in an all-round way?' $21.8 \%$ of the students are very willing to choose, $56.7 \%$ are willing to choose, $15 \%$ are general, $7.5 \%$ are unwilling to choose, and no one is very unwilling to choose. This shows that we are still looking forward to the promotion of this blended experimental teaching model based on cloud platform. Overall, the questionnaire survey shows that the blended experimental teaching mode based on cloud platform has achieved good results.

\section{SUMMARY}

The mixed experimental teaching mode based on cloud platform embodies the "student-centered" teaching mode. It constructs an integrated experimental cloud platform with multi-functions such as experimental content learning, virtual training, online question answering, interactive discussion and self-test. It adopts the experimental mode of "combination of virtual and real". An all-round online teaching mode is realized. The experiment is open, and the experimental teaching method of "flipping classroom" is adopted. The students learn in advance, simulate training and exchange discussion through the cloud platform, which shortens the time of the real experiment and improves the effect of the experiment. The students are organizers and leaders in the whole experiment process. The teachers are guides. The whole process of the experiment records the learning process of the students. It can comprehensively evaluate the learning effect of students, truly enable students to learn autonomously in thinking, exploration, collaboration and discussion in the learning process, and play a multi-dimensional role in thinking training.

\section{ACKNOWLEDGMENT}

The research work is funded by the 13th Five-Year Education Planning Project of Shandong Province Fund under grant NO. YC201917.

\section{REFERENCES}

[1] Matthew R. Rowles, Craig E. Buckley, Aberration corrections for non Brag-Brentano diffraction geometrie. Journal of Applied Crystallography. 2017, pp. 21-23.

[2] Yi Cheng, Shiyong Zhao, Bernt Johannessen, Jean - Pierre Veder, Martin Saunders, Matthew R. Rowles, Min Cheng, Chang Liu, Matthew F. Chisholm, Roland Marco, Hui - Ming Cheng, Shi - Ze Yang, San Ping Jiang. Single - Atom Catalysts: Atomically Dispersed Transition Metals on Carbon Nanotubes with Ultrahigh Loading for Selective Electrochemical Carbon Dioxide Reduction (Adv. Mater. 13/2018). Advanced Materials. 2018, pp.68-73.

[3] Matthew R. Rowles, Mark J. Styles, Ian C. Madsen, Nicola V. Y. Scarlett, Katherine McGregor, Daniel P. Riley, Graeme A. Snook, Andrew J. Urban, Thomas Connolley, Christina Reinhard. Quantification of passivation layer growth in inert anodes for molten salt electrochemistry by in situ energy - dispersive diffraction. Journal of Applied Crystallography. 2012, pp.132-133

[4] Vanissorn Vimonsatit, Trevor Htut. Civil Engineering students' response to visualisation learning experience with building information model. Australasian Journal of Engineering Education. 2016, pp.217-218.

[5] Tian Sing Ng, Stephen J. Foster, Maung Linn Htet, Trevor Nyan Soe Htut. Mixed mode fracture behavior of steel fiber reinforced concrete. Materials and Structures. 2014, pp.217-21

[6] Cheng Cheng Wang, Shuai He, Kongfa Chen, Matthew R. Rowles, Shadi Darvish, Yu Zhong, San Ping Jiang. Effect of SO2 Poisoning on the Electrochemical Activity of La0.6Sr0.4Co0.2Fe0.8O3- $\delta$ Cathodes of Solid Oxide Fuel Cells. Journal of the Electrochemical Society. 2017, pp.17-21.

[7] https://campustechnology.com/articles/2016/10/12/55-percent-offaculty-are-flipping-the-classrom.aspx.

[8] Adams Becker S, Cummins M, Davis A, etc. NMC Horizon Report 2017 Higher Education Edition. Austin, Texas: The New Media Consortium, 2017, pp.32-33.

[9] Kozik T, Simon M. Preparing and managing the remote experiment in education $[\mathrm{C}] / / 2012$ 15th International Conference on Interactive Collaborative Learning. Villach: IEEE, 2012, pp. 56-57. 